\title{
Eco-physiological studies on desert plants: germination of Halothamnus iraqensis Botsch. seeds under different conditions
}

\author{
Arvind BHATT ${ }^{1 *}$, Narayana R BHAT ${ }^{1}$, Valentina MURRU ${ }^{2}$, Andrea SANTO $^{3}$ \\ ${ }^{1}$ Kuwait Institute for Scientific Research, Safat 13109, Kuwait; \\ ${ }^{2}$ University of Cagliari, Cagliari 09123, Italy; \\ ${ }^{3}$ Independent Researcher, Selargius 09047, Italy
}

\begin{abstract}
With the aim to investigate if the halophyte Halothamnus iraqensis Botsch. can be suitable for re-vegetation and remediation of salt-affected lands, this study evaluated (1) the effects of photoperiod, thermoperiod, storage period and wings' presence on its seed germination, and (2) the ability of its seeds to have successful germination recovery after salt stress. Germination tests in different photoperiods $(12 \mathrm{~h}$ light $/ 12 \mathrm{~h}$ darkness and total darkness) and thermoperiods $\left(15^{\circ} \mathrm{C} / 20^{\circ} \mathrm{C}\right.$ and $\left.20^{\circ} \mathrm{C} / 25^{\circ} \mathrm{C}\right)$ were conducted for seeds collected in 2012, 2013, 2014, 2015 and 2016. The seeds collected in 2016 were sown under different salinity levels $(0,100,200,400$ and $600 \mathrm{mM} \mathrm{NaCl})$ to assess the salinity tolerance during the germination. Wings' presence highly inhibited seed germination of this species in both photoperiods and thermoperiods under all salinity level treatments. In addition, the germination recovery occurred well when seeds were deprived of their wings. The photoperiod of $12 \mathrm{~h} \mathrm{light} / 12 \mathrm{~h}$ darkness and the thermoperiod of $15^{\circ} \mathrm{C} / 20^{\circ} \mathrm{C}$ were the best conditions for seed germination. Germination percentages of $H$. iraqensis seeds decreased with the increasing storage duration, especially after three years of the collection. In addition, $H$. iragensis seeds were able to germinate under different salinity levels, and their germination percentages decreased with increasing salinity levels. H. iraqensis seeds have the ability to recover their germination after alleviating the salt stress, irrespective of photoperiod, highlighting the halophilous character of this species.
\end{abstract}

Keywords: wings' presence; storage period; photoperiod; thermoperiod; salt stress; Halothamnus iraqensis Botsch.

Citation: Arvind BHATT, Narayana R BHAT, Valentina MURRU, Andrea SANTO. 2019. Eco-physiological studies on desert plants: germination of Halothamnus iraqensis Botsch. seeds under different conditions. Journal of Arid Land, 11(1): 75-85. https://doi.org/10.1007/s40333-019-0121-7

\section{Introduction}

Desert species are well adapted to cope with high temperatures, irregular water availability and high salinity, hence they are able to successfully colonize and survive under harsh environmental conditions (Khan and Weber, 2006; Rewald et al., 2011). Substrate salinity is one of the factors that mainly affects species germination and growth in arid and semi-arid regions (Paul, 2012; Flowers and Colmer, 2015; Song and Wang, 2015; Bhatt and Santo, 2017a). Halophytes have the ability to adapt to the dry saline soil conditions through morphological, anatomical and physiological adaptations (Flowers and Colmer, 2008; Hasanuzzaman et al., 2014; Song and Wang, 2015). Therefore, planting halophytic plants could be a potential way to rehabilitate the salt-affected lands

\footnotetext{
*Corresponding author: Arvind BHATT (E-mail: drbhatt79@gmail.com)

Received 2018-03-15; revised 2018-05-02; accepted 2018-06-21

C Xinjiang Institute of Ecology and Geography, Chinese Academy of Sciences, Science Press and Springer-Verlag GmbH Germany, part of Springer Nature 2019
} 
in arid and semi-arid regions. Furthermore, halophytes might be used as fodder and fuel or for medicinal purposes (Hasanuzzaman et al., 2014; Gairola et al., 2015; Song et al., 2016; Xu et al., 2016).

Seed germination is one of the most important phases in the life cycle of halophytes and germination responses to different environmental factors play an important role in determining their distribution in saline environments (Song et al., 2005; Li et al., 2010). In particular, under natural conditions, germination of halophytic species is controlled by environmental factors such as light (Huang et al., 2003, Bhatt et al., 2016a), temperature (El-Keblawy et al., 2013; Bhatt et al., 2016b) and soil salinity (Khan et al., 2002; El-Keblawy and Bhatt, 2015; Bhatt and Santo, 2016). The requirement to adapt to each of these environmental factors varies among species, and therefore each halophyte responds differently during its seed germination phase (Khan and Ungar, 1997; Noe and Zedler, 2000).

The ex-situ storage of germplasm is a necessary step for the long-term conservation of rare and endangered species, and the duration of successful storage without the loss of seed viability varies among species. Thus, knowing the seed longevity of a species is essential for its effective management and long-term conservation (Li et al., 2008; Xu et al., 2016). Seed banks are widely used for the conservation of threatened and economically important species, due to the possibility to conserve large amounts of genetic diversity (seeds) within a small volume, and consequently with relatively low management costs (Martin et al., 2001). However, seed storage may often negatively influence seed viability in relation to conditions (e.g., temperature and humidity) and time of storage (Shaban, 2013; Mahmood et al., 2016). It is a fundamental part of maintaining a seed bank by continuous monitoring seed viability through germination testing at regular intervals, which allows evaluating the genetic and physiological erosion during the storage period (Ruiz et al., 1999). Some studies have been already conducted to assess the seed viability after ex-situ storage of some desert halophytes, such as Salsola imbricata (Zaman et al., 2010; El-Keblawy, 2014), Zygophyllum qatarense (Zaman, 2013) and Haloxylon salicornicum (El-Keblawy, 2014). However, the effects of storage on seed viability are unknown for most of the desert halophytes.

The genus Halothamnus Jaubert \& Spach belongs to the Amaranthaceae family and comprises 21 species distributed in arid and semi-arid habitats of Saudi Arabia, United Arab Emirates (UAE), Yemen, Kuwait, Turkey, Armenia, China, Pakistan and Afghanistan (Kothe-Heinrich, 1993; Musaddiq et al., 2015). Several species of this genus are used as fodder and for medicinal purposes (Kinzikaeva, 1968; Musaddiq et al., 2015). Previous studies confirmed that all the species of Halothamnus have a unique $\mathrm{C}_{4}$ photosynthesis mechanism and this gives them more resistance to drought and high salinity as compared to $\mathrm{C}_{3}$ plants (Zalensky 1981; Yin and Wang, 1997).

Halothamnus iraqensis Botsch. is a perennial branched shrub that grows up to $50 \mathrm{~cm}$ in height. It is widely spotted in Saudi Arabia, UAE, Kuwait, Oman and Iraq (Kothe-Heinrich, 1993). The seeds of $H$. iraqensis are enclosed by a persistent wing which is retained in the mature fruit with the pericarp (Mandaville, 2011). The wings' presence helps this species in its seed dispersal, which occurs through anemochory (Kothe-Heinrich, 1993). Most species of the Halothamnus (including $H$. iraqensis) which are frequently grazed by camels, sheep and goats have excellent sand-fixation ability and can tolerate extreme temperatures, high drought and high salinity. Therefore, $H$. iraqensis has the potential to be used for rehabilitating the degraded arid and salt-affected lands (Kinzikaeva, 1968). However, until now, there is no information available on the effects of long-term seed storage and role of wing on its seed germination and salinity tolerance. It could be in help for restoration or rehabilitation of salt-stressed habitats to understand the long-term seed storage behavior of $H$. iraqensis (Fenner and Thompson, 2005; Liu et al., 2011).

The aims of this study were to investigate the effects of photoperiod, thermoperiod, storage period and wings' presence on the germination of $H$. iraqensis seeds and the ability of the seeds to have successful germination recovery after alleviating the salt stress. 


\section{Materials and methods}

\subsection{Study area}

Kuwait is characterized by a desert climate with a long, dry and hot summer and a cool winter. The day time temperature usually exceeds $50^{\circ} \mathrm{C}$ in summer and below $4{ }^{\circ} \mathrm{C}$ in winter (Annual Statistical Report, 2006). Precipitation is scarce, with less than $114 \mathrm{~mm}$ annually and mostly occurring in October to March in the next year (Omar et al., 2007). Soil in Kuwait is mostly sandy with high infiltration rate and is calcareous in nature (Omar et al., 2007).

\subsection{Seeds collection}

Seeds of $H$. iraqensis were collected from a natural vegetation population in Julaia, Kuwait $\left(28^{\circ} 53^{\prime} 29^{\prime \prime} \mathrm{N}, 48^{\circ} 14^{\prime} 17^{\prime \prime} \mathrm{E}\right)$, in the period of their natural dispersal (December) in 2012-2016. The seeds were collected from 50 randomly selected plants and mixed together to represent the genetic diversity of the population. They were then stored in brown paper bags at room temperature $\left(20^{\circ} \mathrm{C} \pm 2^{\circ} \mathrm{C}\right)$ in Kuwait Institute for Scientific Research (KISR) Seed Bank until the experiment started in December 2016. The seeds collected in 2016 were used for the experiments within a week after the collection. When the seeds were used for the experiments after the storage, the seed lot collected during each year was divided into two sub-lots, in which one lot of seeds was deprived of wings (de-winged seeds; wings were carefully removed by hand) and the other remained intact (winged seeds or intact seeds). The seed mass of the lot for each year was determined by weighing three replicates of 50 seeds each.

\subsection{Effects of photoperiod, thermoperiod, storage period and wings' presence on seed germination}

The seeds of $H$. iraqensis collected in 2012-2016 were incubated in two growth chambers to investigate the photoperiod and thermoperiod requirements during the germination. The chambers were set at night/day $(12 \mathrm{~h} / 12 \mathrm{~h})$ temperature regimes of $15^{\circ} \mathrm{C} / 20^{\circ} \mathrm{C}$ and $20^{\circ} \mathrm{C} / 25^{\circ} \mathrm{C}$ in either continuous darkness (dark treatment) and $12 \mathrm{~h}$ light $/ 12 \mathrm{~h}$ darkness (light treatment). In the dark treatment, the petri-dishes were wrapped in two layers of aluminum foils to prevent any exposure to light. The germination tests were conducted in 9-cm petri dishes containing three disks of Whatman No. 1 filter paper moistened with $10 \mathrm{~mL}$ of distilled water. Four replicates of 25 seeds each were used for each treatment. The seeds were considered to be germinated with the emergence of the radicle $(\geq 2 \mathrm{~mm})$. Germinated seeds were counted and removed daily for a $30 \mathrm{~d}$ period. However, seeds incubated in the dark were checked only at the end of the test. At the end of the germination test, the ungerminated seeds were dissected to evaluate the embryo status and viabilities (living and therefore white; turgid and brown and therefore dead) under a binocular microscope. The permeability of winged and de-winged seeds, was evaluated by measuring the seed weight after an imbibition test in distilled water for $24 \mathrm{~h}$.

\subsection{Effects of salinity on seed germination}

Germination tests under different salinity levels $(0,100,200,400$ and $600 \mathrm{mM} \mathrm{NaCl})$ were conducted to assess the salinity tolerance for seeds of $H$. iraqensis collected in 2016. Four replicates of 25 seeds each were used per treatment for both winged and de-winged seeds. Seeds were sown in 9-cm diameter petri dishes on three layers of Whatman No. 1 filter paper, moistened with $10 \mathrm{~mL}$ of the saline solution for each salinity level. The petri dishes were sealed with parafilm to minimize evaporation and external contamination. The petri dishes were incubated at $15^{\circ} \mathrm{C} / 20^{\circ} \mathrm{C}$ in either dark or light treatments. For the dark treatment, the dishes were wrapped in aluminum foils as described above. Germinated seeds were counted and removed every day for the light treatment and were counted at the end of the test for the dark treatment.

\subsection{Germination recovery}

The seeds failed the salinity tolerance test were placed in petri dishes with distilled water to germinate again under the same conditions of the experiments mentioned above to test the effects of photoperiod and thermoperiod. The germinated seeds were counted in the same way as the other 
experiments. At the end of the germination test, the ungerminated seeds were dissected to evaluate the embryo status and viabilities under a binocular microscope.

\subsection{Data analysis}

The germination percentage was calculated as the mean percentage of the four replicates (standard deviation, $\mathrm{SD}$ ), and the recovery percentage (RP) was calculated by the following equation:

$$
\mathrm{RP}=[(a-b) /(c-b)] \times 100 \%,
$$

where $a$ is the total number of seeds germinated gonging through the salinity tolerance test plus those that germinated again in the germination recovery stage, $b$ is the total number of seeds germinated gonging through the salinity tolerance test and $c$ is the total number of seeds used in the salinity tolerance test (Khan et al., 2000; Bhatt and Santo, 2016).

The Shapiro-Wilk test was conducted to evaluate the normality before the subsequent analyses. Arcsine-transformed germination percentages were analyzed by ANOVA and consequent Fisher's least significant differences (LSD) post-hoc test. Data were graphed using Sigmaplot 11.0 (Systat Software Inc., London, UK) and the statistical analyses were carried out using Statistica 7.0 for Windows (Software Statsoft Release 7).

\section{Results}

\subsection{Effects of photoperiod, thermoperiod, storage period and wings' presence on seed germination}

The mean seed mass values of winged and de-winged seeds of $H$. iraqensis were 9.7 and $4.3 \mathrm{mg}$, respectively. $H$. iraqensis seeds germinated differently $(P<0.001)$ under different treatments including photoperiod, thermoperiod, storage period and wings' presence (Table 1). The treatments of the above factors and their interactions showed highly significant $(P<0.001)$ effects on the germination percentages of $H$. iraqensis seeds, with exceptions of the interactions among photoperiod, thermoperiod and wings' presence, and among photoperiod, thermoperiod, storage period and wings' presence, which only showed significant effect $(P<0.05)$. Furthermore, the interaction between photoperiod and thermoperiod showed no-significant effect $(P>0.05)$ on the germination percentages of $H$. iraqensis seeds.

Table 1 Effects of photoperiod, thermoperiod, storage period, wings' presence and their interactions on the germination percentage of $H$. iraqensis seeds

\begin{tabular}{|c|c|c|c|c|c|}
\hline Treatment & SS & $d f$ & MS & $F$ & $P$ \\
\hline Photoperiod (P) & 7182.42 & 1 & 7182.42 & 424.157 & $* * *$ \\
\hline Thermoperiod (T) & 435.61 & 1 & 435.61 & 25.724 & $* * *$ \\
\hline Storage period $(\mathrm{Y})$ & $24,529.43$ & 4 & 6132.45 & 362.147 & $* * *$ \\
\hline Wings'presence (W) & $147,379.64$ & 1 & $147,379.65$ & 8703.520 & $* * *$ \\
\hline $\mathrm{P} \times \mathrm{T}$ & 25.60 & 1 & 25.64 & 1.512 & ns \\
\hline $\mathrm{P} \times \mathrm{Y}$ & 826.67 & 4 & 206.73 & 12.204 & $* * *$ \\
\hline $\mathrm{T} \times \mathrm{Y}$ & 657.46 & 4 & 164.42 & 9.706 & $* * *$ \\
\hline $\mathrm{P} \times \mathrm{W}$ & 5017.68 & 1 & 5017.67 & 296.315 & $* * *$ \\
\hline $\mathrm{T} \times \mathrm{W}$ & 739.61 & 1 & 739.63 & 43.677 & $* * *$ \\
\hline $\mathrm{Y} \times \mathrm{W}$ & $17,457.43$ & 4 & 4364.42 & 257.737 & $* * *$ \\
\hline $\mathrm{P} \times \mathrm{T} \times \mathrm{Y}$ & 443.43 & 4 & 110.90 & 6.546 & $* * *$ \\
\hline $\mathrm{P} \times \mathrm{T} \times \mathrm{W}$ & 102.40 & 1 & 102.44 & 6.047 & * \\
\hline $\mathrm{P} \times \mathrm{Y} \times \mathrm{W}$ & 1199.42 & 4 & 299.85 & 17.708 & $* * *$ \\
\hline $\mathrm{T} \times \mathrm{Y} \times \mathrm{W}$ & 553.40 & 4 & 138.40 & 8.170 & $* * *$ \\
\hline $\mathrm{P} \times \mathrm{T} \times \mathrm{Y} \times \mathrm{W}$ & 166.60 & 4 & 41.70 & 2.460 & $*$ \\
\hline Error & 2032.04 & 120 & 16.96 & & \\
\hline
\end{tabular}

Note: ns, no significant correlation at $P>0.05$ level; *, significant correlation at $P<0.05$ level; ***, highly significant correlation at $P<0.001$ level. SS, sum of squares; $d f$, degrees of freedom; MS, mean square; $F$, fisher variable. 


\subsubsection{Temperature at $15^{\circ} \mathrm{C} / 20^{\circ} \mathrm{C}$}

In the light treatment, only the winged seeds collected in 2016 showed germination ability of germination percentage $(12 \%)$, while winged seeds collected in other years were unable to germinate (Fig. 1a). The de-winged seeds collected in all years were able to germinate with the highest germination percentage of 93\% observed for the seeds collected in 2014, 2015 and 2016, while the lowest germination percentage of $40 \%$ was appeared in the de-winged seeds collected in 2012. The same pattern was observed in the dark treatment but with significantly lower germination percentages compared with the light treatment (Fig. 1b). In particular, the de-winged seeds of 2016 showed an absolutely high germination percentage of $80 \%$ in the dark treatment.

\subsubsection{Temperature at $20^{\circ} \mathrm{C} / 25^{\circ} \mathrm{C}$}

In the light treatment, the germination percentage was only $2 \%$ for the winged seeds collected in 2014 and 2015, and was 20\% for the winged seeds collected in 2016 (Fig. 1c). The de-winged seeds of all years germinated and the seeds collected in 2015 and 2016 had the highest germination percentage $(96 \%)$. With respect to the light treatment, the winged seeds in the dark treatment showed lower germination percentages than those in the light treatment and had no significant difference among the winged seeds collected in 2014, 2015 and 2016 (Fig. 1d). Moreover, the de-winged seeds also showed lower germination percentages in the dark treatment. Only the de-winged seeds collected in 2016 reached the highest germination percentage of $70 \%$.

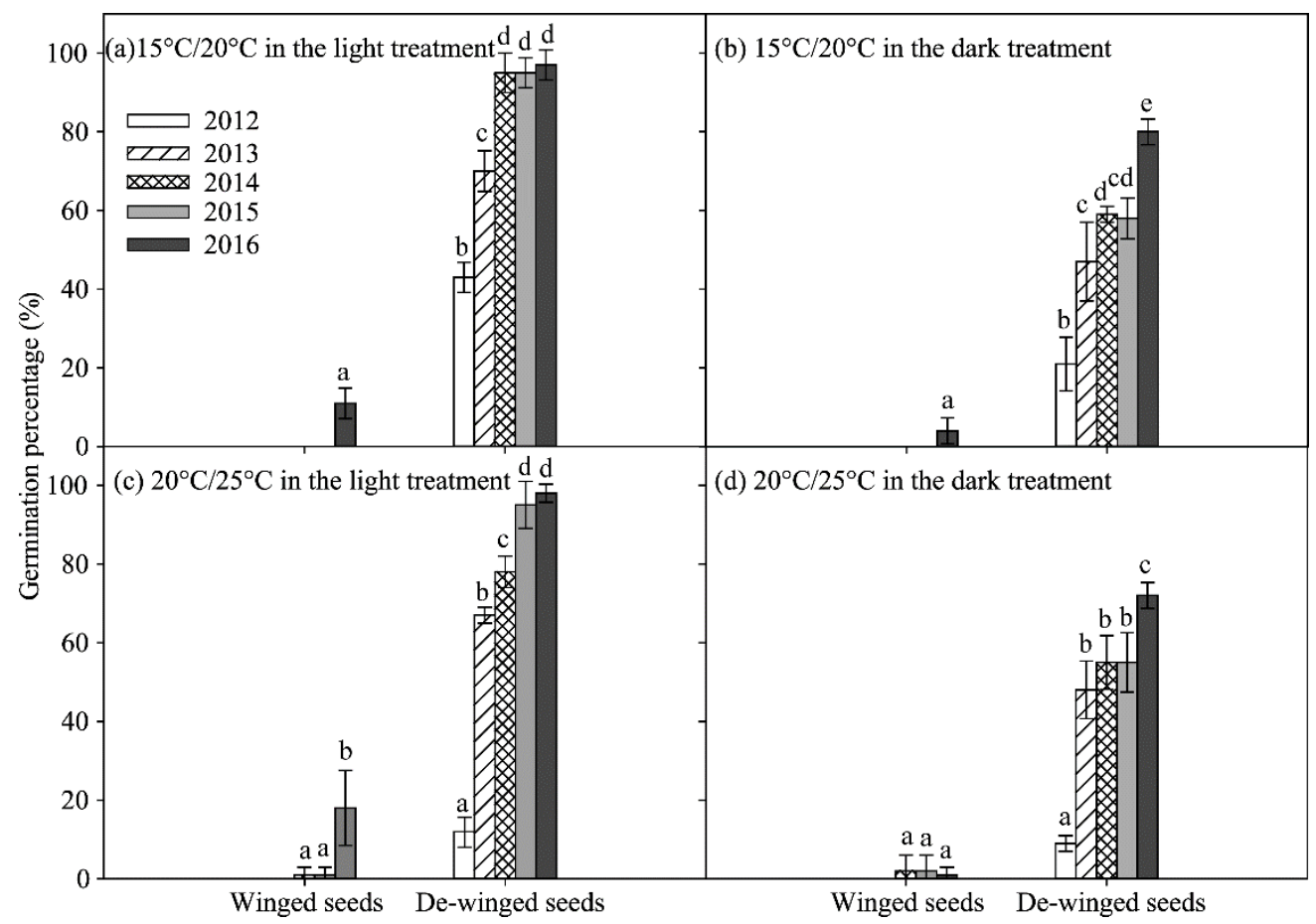

Fig. 1 Germination percentages of winged and de-winged seeds of $H$. iraqensis collected in 2012, 2013, 2014, 2015 and 2016 under different photoperiod and thermoperiod treatments

\subsection{Effects of salinity on seed germination at $15^{\circ} \mathrm{C} / 20^{\circ} \mathrm{C}$}

The photoperiod, wings' presence and salinity and their interactions significantly $(P<0.001)$ influenced the germination percentages of $H$. iraqensis seeds (Table 2). In the light or dark treatment with different salinity levels $(0,100,200,400$ and $600 \mathrm{mM} \mathrm{NaCl})$, no more than $12 \%$ of winged seeds germinated and the highest germination percentage occurred in total absence of $\mathrm{NaCl}$ (Fig. 2). In the light treatment, the germination percentages of de-winged seeds decreased with salinity increasing, ranging from $97 \%$ under $0 \mathrm{mM} \mathrm{NaCl}$ to $28 \%$ under $600 \mathrm{mM} \mathrm{NaCl}$. The same pattern of de-winged seeds was observed in the dark treatment, with the germination percentages ranged from $80 \%$ under $0 \mathrm{mM} \mathrm{NaCl}$ to $20 \%$ under $600 \mathrm{mM} \mathrm{NaCl}$. 
Table 2 Effects of photoperiod, wings' presence, salinity and their interactions on the germinations percentage of H. iraqensis seeds

\begin{tabular}{crrrrrr}
\hline Treatment & \multicolumn{1}{c}{ SS } & df & \multicolumn{1}{c}{ MS } & \multicolumn{1}{c}{$F$} & $P$ \\
\hline Photoperiod (P) & 3864.20 & 1 & 3864.20 & 206.274 & $* * *$ \\
Wings' presence (W) & $68,913.80$ & 1 & $68,913.80$ & 3678.673 & $* * *$ \\
Salinity (S) & $12,316.80$ & 4 & 3079.20 & 164.370 & $* * *$ \\
$\mathrm{P} \times \mathrm{W}$ & 2928.20 & 1 & 2928.20 & 156.310 & $* * *$ \\
$\mathrm{P} \times \mathrm{S}$ & 744.80 & 4 & 186.20 & 9.940 & $* * *$ \\
$\mathrm{~W} \times \mathrm{S}$ & 8831.20 & 4 & 2207.80 & 117.854 & $* * *$ \\
$\mathrm{P} \times \mathrm{W} \times \mathrm{S}$ & 964.80 & 4 & 241.20 & 12.875 & $* * *$
\end{tabular}

Note: ***, highly significant correlation at $P<0.001$ level.

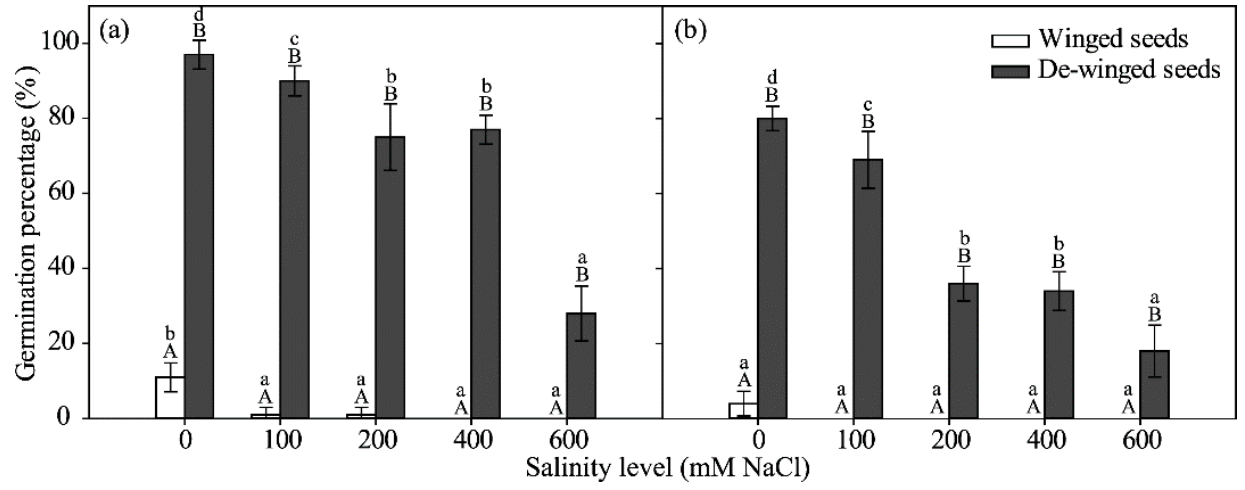

Fig. 2 Germination percentages of winged and de-winged seeds of $H$. iraqensis at $15^{\circ} \mathrm{C} / 20^{\circ} \mathrm{C}$ in the light treatment (a) and in the dark treatment (b) under different salinity levels (0, 100, 200, 400 and $600 \mathrm{mM} \mathrm{NaCl})$. Bars mean standard deviations. Different capital letters indicate the significant differences among winged and de-winged seeds under the same salinity level at $P<0.001$ level. Different lowercase letters indicate the significant differences among the salinity levels for winged or de-winged seeds at $P<0.05$ level.

\subsection{Germination recovery after salt exposure}

The unique factor which highly significantly influenced $(P<0.001)$ the germination recovery percentages of $H$. iraqensis seeds was the wings' presence. The photoperiod, salinity and the interactions of photoperiod, wings' presence and salinity had no significant influence on the germination recovery of $H$. iraqensis seeds (Table 3 ). No more than $15 \%$ of winged seeds had the ability to recover the germination after the salinity tolerance test (Fig. 3). When seeds were deprived of their wings, the germination recovery percentage increased considerably by $60 \%$ in the light treatment and at least $50 \%$ in the dark treatment. At the end of the germination recovery test, the ungerminated seeds were dissected to evaluate the embryo status and viabilities under a binocular microscope, and no more than $5 \%$ of seeds were dead.

Table 3 Effects of photoperiod, wings' presence, salinity and their interactions on the germination recovery percentages of $H$. iraqensis seeds after salt exposure and washed with distilled water

\begin{tabular}{|c|c|c|c|c|c|}
\hline Treatment & SS & $d f$ & MS & $F$ & $P$ \\
\hline Photoperiod (P) & 240.95 & 1 & 240.95 & 2.339 & ns \\
\hline Wings' presence $(\mathrm{W})$ & $43,777.19$ & 1 & $43,777.19$ & 425.015 & $* * *$ \\
\hline Salinity (S) & 57.00 & 3 & 19.00 & 0.185 & ns \\
\hline $\mathrm{P} \times \mathrm{W}$ & 12.98 & 1 & 12.98 & 0.126 & ns \\
\hline $\mathrm{P} \times \mathrm{S}$ & 125.88 & 3 & 41.96 & 0.407 & ns \\
\hline $\mathrm{W} \times \mathrm{S}$ & 433.81 & 3 & 144.60 & 1.404 & ns \\
\hline $\mathrm{P} \times \mathrm{W} \times \mathrm{S}$ & 373.04 & 3 & 124.35 & 1.207 & ns \\
\hline Error & 4944.07 & 48 & 103.00 & & \\
\hline
\end{tabular}




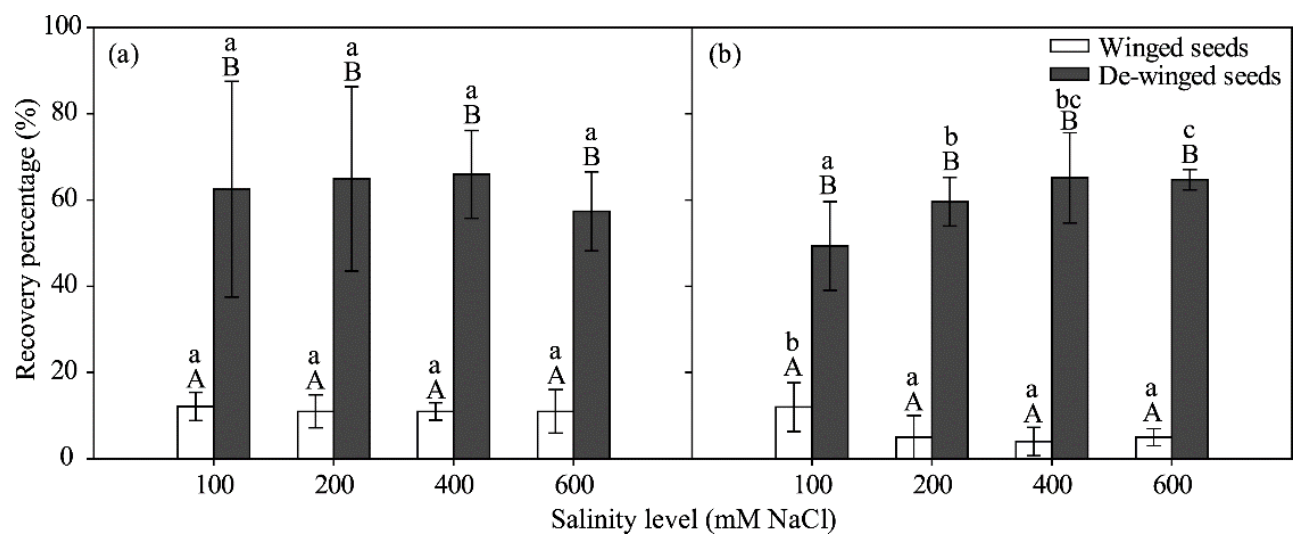

Fig. 3 Germination recovery percentages of winged and de-winged seeds of $H$. iraqensis at $15^{\circ} \mathrm{C} / 20^{\circ} \mathrm{C}$ in the light treatment (a) and in the dark treatment (b) after the exposure to different salinity levels (100, 200, 400 and $600 \mathrm{mM}$ $\mathrm{NaCl}$ ). Bars mean standard deviations. Different capital letters indicate the significant differences among winged and de-winged seeds under the same salinity level at $P<0.001$ level. Different lowercase letters indicate the significant differences among the salinity levels for winged or de-winged seeds at $P<0.05$ level.

\section{Discussion}

\subsection{Effects of photoperiod on the germination of $\boldsymbol{H}$. iraqensis seeds}

Our results showed that the light treatment significantly enhanced the germination percentages of $H$. iraqensis de-winged seeds, indicating that these seeds are light-dependent (positively photoblastic, however, they are also able to germinate in the total darkness). Therefore, they might have a higher ability of germination if they remain at or near the soil surface when other environmental conditions (e.g., moisture availability, optimal temperature, etc.) are favourable. The light-mediated germination of $H$. iraqensis seeds might be an adaptation strategy to avoid their germination too deep under the soil, where conditions could be insufficient for successful seedling emergence due to the low energy reserves (Milberg et al., 2000).

\subsection{Effects of thermoperiod on the germination of $\boldsymbol{H}$. iraqensis seeds}

As shown in Figure 1, H. iraqensis seeds collected in 2012-2014 showed significantly higher germination percentages at $15^{\circ} \mathrm{C} / 20^{\circ} \mathrm{C}$ than at $20^{\circ} \mathrm{C} / 25^{\circ} \mathrm{C}$; however, the thermoperiod had no obvious impacts on the seeds collected in 2015 and 2016. Generally, seeds go through various physiological changes during storage, such as the loss of dormancy, temperature and light sensitivity (Bewley and Black, 1982; Probert, 2000). Therefore, we believe that the germination temperature would be different for seeds with different storage durations. Based on our results, combined with the local meteorological data (not shown), we speculate that $H$. iraqensis seeds could germinate well in January to April with the temperature of $13^{\circ} \mathrm{C}-25^{\circ} \mathrm{C}$ if the seeds were kept for no more than two years. Furthermore, if the seeds were kept for more than two years, the better germination season is January to March with the temperature of $13^{\circ} \mathrm{C}-19^{\circ} \mathrm{C}$. Based on the seed storage duration, different adaptation strategies can help the species to survive in the harsh environmental conditions.

\subsection{Effects of wings' presence on the germination of $\boldsymbol{H}$. iraqensis seeds}

The results obtained in our study demonstrated that the presence of wings, independent of all the other factors, highly inhibited the seed germination of $H$. iraqensis and imposed seed dormancy, indicating that the wing of this species probably contains inhibitors. In Aellenia autrani (Post) Zoh., the presence of persistent wing has been found responsible for the leading seed dormancy (Negbi and Tamari, 1963); and in Halothamnus subaphyllus (C.A. Meyer) Botsch., the wing was reported to contain germination inhibitors, e.g., phenolic components, abscisic acid and nicotinic acid (Ionesova, 1970). The presence of wing was also reported to cause the physiological dormancy in several species of Amaranthaceae (Baskin and Baskin, 2014; Bhatt and Santo, 2017b). 
Specifically, the presence of wing can inhibit the germination of a species, being a mechanical barrier for seed radicle growth. Moreover, the wing presence can reduce the correct water absorption because the wing is a tissue that can accumulate chloride ions or high concentrations of abscisic acid (Takeno and Yamaguchi, 1991; El-Keblawy et al., 2013; Xing et al., 2013; Bhatt et al., $2016 \mathrm{a}, \mathrm{b}$ ). In this study, both winged and de-winged seeds of $H$. iraqensis were able to absorb water, which means that wing will not stopped the correct water absorption, however it does inhibit the seed germination. In our case, some winged seeds ( $<19 \%$; Figs. 1 and 2) collected in 2014, 2015 and 2016 were able to germinate, indicating that the wing might not be fully rigid at that time to create a mechanical barrier for radicle emergence. However, the wing might become more rigid with storage duration, which might explain why the seeds with longer storage duration did not germinate. Further investigations are needed for a better understanding of the germination inhibition mechanism due to the wings' presence.

\subsection{Effects of storage period on the germination of $H$. iraqensis seeds}

Germination percentages of $H$. iraqensis seeds decreased with the increasing storage duration, especially after three years of the collection. This might be caused by the aging of the seeds or the storage conditions. Storage duration can alter the endogenous hormone level and seed-coat phenolics, which ultimately affect the seed germination. With the increasing storage duration, phenolics and abscisic acid concentrations significantly increased (Li et al., 2008; Xu et al., 2016). Thus, decreasing level of gibberellic acid and increasing phelolics combined with the increasing storage duration of $H$. iraqensis seeds could be responsible for the poor germination. In this study, $H$. iraqensis seeds were able to maintain the germination percentages up to $95 \%$ and $70 \%$ after the collection for three and four years, respectively, under the photoperiod and thermoperiod of $12 \mathrm{~h} / 12$ $\mathrm{h}$ of light at $15^{\circ} \mathrm{C} / 20^{\circ} \mathrm{C}$ or $20^{\circ} \mathrm{C} / 25^{\circ} \mathrm{C}$, indicating that the seeds are tolerant to desiccation and can be successfully stored at room temperature up to 3-4 years without excessive loss of their viability. In the natural desert habitat, the longevity of seeds may be attributed to the presence of persistent wing by providing physical and chemical barriers to the unfavorable and unpredictable desert environmental conditions. In this study, seeds were stored with the presence of wing at room temperature and wings were only removed at the time of the test and therefore our results can be predictive about the possibility of seed longevity under natural conditions. However, further studies are needed to determine how seeds without wings can maintain their viability if they are stored in similar conditions of the winged seeds in our study.

\subsection{Effects of salinity on the germination of $\boldsymbol{H}$. iraqensis seeds}

$H$. iraqensis seeds, when deprived of the wings, have better ability to germinate under all the tested salinity levels. On the contrary, when wings were maintained, only less than $2 \%$ of seeds germinated under all the tested salinity levels (Fig. 2). This pattern might be an indication that wing is likely a source of accumulation of salts which inhibit the germination in this species as reported in other species of Amaranthaceae (Baskin and Baskin, 2014). Germination percentages of $H$. iraqensis seeds decreased with increasing salinity level, but a very high germination percentage (77\%) was recorded for de-winged seeds under $400 \mathrm{mM} \mathrm{NaCl}$, reflecting the reasonably high salinity tolerance of seeds of this species. These findings indicate that $H$. iraqensis has the potential to be used in salt-affected lands by sowing its seeds directly instead of planting adult individuals, which can greatly reduce the economic costs of restoration ecology activities. When the $H$. iraqensis seeds are sown in saline substrate, germination percentages are higher in the light treatment than in the dark treatment, and increasing salinity negatively affected germination percentages in the dark treatment as compared to the light treatment. This pattern might indicate that seeds remain near the soil surface could be able to germinate even with few rainfall events that could reduce the surface salinity. However, if they are buried too deep in the soil, the unavailability of light, together with the higher salinity level, could reduce the possibility of their germination. Our results are in accordance with previous studies (El-Keblawy and Bhatt, 2015; Bhatt et al., 2016a, b; El-Keblawy et al., 2016) which reported that light and salinity have positive interactive effects on seed germination compared with the total darkness in presence of salinity and, therefore, 
some of the halophyte seeds germinate better in presence of light when salts are also present in the substrate.

\subsection{Germination recovery}

Our results indicated that ungerminated seeds under different salinity levels of $H$. iraqensis were able to recover their germination ability after alleviating the salt stress by transferring them to distilled water. However, the winged seeds have very low germination recovery percentages as compared to the de-winged seeds, indicating that the presence of wing has negative effects on the germination recovery after the salinity tolerance test (Fig. 3). The winged seeds showed very poor germination under the highest tested salinity level $(600 \mathrm{mM} \mathrm{NaCl})$, but their germination percentages increased by transferring them to distilled water. Similar results were obtained for Salsola affinis (Wei et al., 2008). Studies on other species (Cordazzo, 1994; Keiffer and Ungar, 1997) showed that the salinity might weaken the effects of wing on seed germination and stimulate the germination of winged seeds, but this was not the case for $\mathrm{H}$. iraqensis, for which winged seeds had very low germination percentages under all the tested salinity levels (with respect to de-winged seeds). The germination recovery ability of $H$. iraqensis seeds was influenced exclusively by wings' presence, while the photoperiod and salinity level had no effect on the germination recovery percentages.

Our findings showed that $H$. iraqensis seeds can maintain viable during high salt exposure and they might be able to germinate after being washed with distilled water. Similar results were obtained from other desert halophytic species, when the ungerminated seeds from saline solutions were transferred to distilled water (El-Keblawy et al., 2013; Bhatt et al., 2016a, b). It is a well-known fact that the germination recovery ability of seeds is a species-specific property both in halophyte and salt tolerant species (Ungar, 1995, Song et al., 2005). From a natural viewpoint, in the field, this ability of $H$. iraqensis seeds to maintain viable under high salinity level might be an evolved physiological adaptation which helps the seeds to survive under the saline desert habitat conditions. From a practical viewpoint, this property indicates that $H$. iraqensis seeds can be sown in salt-stressed habitats or the salinized land because they can help the recovery of the habitats or land.

\section{Conclusions}

This study allowed the understanding that wings' presence highly inhibits the germination of $H$. iraqensis seeds. In addition, the storage duration affects the germination ability of seeds. Germination percentages of $H$. iraqensis seeds decreased with the increasing storage duration, especially after three years of the collection, indicating that the storage duration should not exceed 2-3 years. Photoperiod and thermoperiod are important factors influencing the germination of $H$. iraqensis seeds. The photoperiod of $12 \mathrm{~h} \mathrm{light} / 12 \mathrm{~h}$ darkness and the thermoperiod of $15^{\circ} \mathrm{C} / 20^{\circ} \mathrm{C}$ are the best conditions for seed germination. Moreover, the results of our study indicate that seeds of $H$. iraqensis are well adapted to saline habitats, which can tolerate high salinity levels in the soil and are able to recover well after alleviating the salt stress.

\section{Acknowledgements}

This study was funded by Kuwait Institute for Scientific Research. The authors are very grateful to Dr. John A MALTON, Dr. Samuel C ALLEN and Prof. Yougasphree NAIDOO for the linguistic revision of the manuscript.

\section{References}

Annual Statistical Report. 2006. Ministry of Planning. Kuwait: Kuwait Central Statistical Bureau, 518.

Baskin C C, Baskin J M. 2014. Seeds: Ecology, Biogeography, and Evolution of Dormancy and Germination (2 ${ }^{\text {nd }}$ ed.). San Diego: Academic Press, 1600.

Bewley J D, Black M. 1984. Physiology and biochemistry of seeds in relation to germination. Plant Ecology, 57(2-3): 115-119.

Bhatt A, Pérez-García F, Mercedes Carón M, et al. 2016a. Germination response of Salsola schweinfurthii (Chenopodiaceae) to 
salinity and winged perianth removal. Seed Science and Technology, 44(2): 428-434.

Bhatt A, Phartyal S S, Nicholas A. 2016b. Ecological role of distinct fruit-wing perianth color in synchronization of seed germination in Haloxylon salicornicum. Plant Species Biology, 32(2): 121-133.

Bhatt A, Santo A. 2016. Germination and recovery of heteromorphic seeds of Atriplex canescens. Plant Ecology, 217(9): 1069-1079.

Bhatt A, Santo A. 2017a. Does perianth colour affect the seed germination of two desert shrubs under different storage periods and conditions? Nordic Journal of Botany, 36(6): 01593, doi.10.1111/njb.01593.

Bhatt A, Santo A. 2017b. Effects of photoperiod, thermoperiod, and salt stress on Gymnocarpos decandrus seeds: potential implications in restoration ecology activities. Botany, 95(11): 1093-1098.

Cordazzo C V. 1994. Comparative population studies of four dominant plants of southern Brazilian coastal dunes. PhD Dissertation. England: University of East Anglia.

El-Keblawy A, Bhatt A, Gairola S. 2013. Perianthcolour affects germination behaviour in wind-pollinated Salsola rubescens in Arabian deserts. Botany, 92(1): 69-75.

El-Keblawy A. 2014. Effects of seed storage on germination of desert halophytes with transient seed bank. In: Khan M A, Böer B, Öztürk M, et al. Sabkha Ecosystems: Volume IV: Cash Crop Halophyte and Biodiversity Conservation. Berlin: Springer Netherlands Press, 93-103.

El-Keblawy A, Bhatt A. 2015. Aerial seed bank affects germination in two small-seeded halophytes in Arab Gulf desert. Journal of Arid Environments, 117: 10-17.

El-Keblawy A, Gairola S, Bhatt A. 2016. Maternal salinity environment affects salt tolerance during germination in Anabasis setifera: A facultative desert halophyte. Journal of Arid Land, 8(2): 254-263.

Fenner M, Thompson K. 2005. The Ecology of Seeds. Cambridge: Cambridge University Press, 260.

Flowers T J, Colmer T D. 2008. Salinity tolerance in halophytes. New Phytologist, 179: 945-963.

Flowers T J, Colmer T D. 2015. Plant salt tolerance: adaptations in halophytes. Annals of Botany, 115(3): 327-331.

Gairola S, Bhatt A, El-Keblawy A. 2015. A perspective on potential use of halophytes for reclamation of salt-affected lands. Wulfenia, 22(1): 88-97.

Hasanuzzaman M, Nahar K, Alam M M, et al. 2014. Potential use of halophytes to remediate saline soils. BioMed Research International, 2014: 1-12.

Huang Z, Zhang X, Zheng G, et al. 2003. Influence of light, temperature, salinity and storage on seed germination of Haloxylonammodendron. Journal of Arid Environments, 55(3): 453-464.

Ionesova A S. 1970. Seed Physiology of Wild-growing Desert Plants. Tashkent: Fan Publishing House of the Uzbek SSR, 150.

Keiffer C H, Ungar I A. 1997. The effect of extended exposure to hypersaline conditions on the germination of five inland halophyte species. American Journal of Botany, 84(1): 104-111.

Khan M A, Ungar I A. 1997. Germination responses of the subtropical annual halophyte Zygophylum simplex. Seed Science and Technology, 25(1): 83-92.

Khan M A, Ungar I A, Showalter A M. 2000. Effects of salinity on growth, water relations and ion accumulation of the subtropical perennial halophyte, Atriplex griffithii var. stocksii. Annals of Botany, 85(2): 225-232.

Khan M A, Gul B, Weber D J. 2002. Seed germination in the Great Basin halophyte Salsola iberica. Canadian Journal of Botany, 80(6): 650-655.

Khan M A, Weber D J. 2006. Ecophysiology of High Salinity Tolerant Plants (Vol. 40). Dordrecht: Springer Science \& Business Media, 397.

Kinzikaeva G K. 1988. Flora Tadzhikskoi SSR. Vol. IX, Marenovye-Slozhnotsvetnye. Leningrad: Nauk Press, 419-425.

Kothe-Heinrich G. 1993. Revision der gattung Halothamnus (Chenopodiaceae). Bibliotheca Botanica, 143: 132-136.

Li R, Shi F, Fukuda K. 2010. Interactive effects of salt and alkali stresses on seed germination, germination recovery, and seedling growth of a halophyte Spartin aalterniflora (Poaceae). South African Journal of Botany, 76(2): 380-387.

Li W, An P, Liu X. 2008. Effect of storage, stratification, temperature and gibberellins on germination of dimorphic seeds of Suaeda salsa under saline conditions. Seed Science and Technology, 36(1): 122-132.

Liu H L, Shi X, Wang J C, et al. 2011. Effects of sand burial, soil water content and distribution pattern of seeds in sand on seed germination and seedling survival of Eremosparton songoricum (Fabaceae), a rare species inhabiting the moving sand dunes of the Gurbantunggut Desert of China. Plant and Soil, 345(1-2): 69-87.

Mahmood A H, Florentine S K, Chauhan B S, et al. 2016. Influence of various environmental factors on seed germination and seedling emergence of a noxious environmental weed: green galenia (Galenia pubescens). Weed Science, 64(3): 486-494.

Mandaville J P. 2011. Bedouin ethnobotany: plant concepts and uses in a desert pastoral world. Arizona: University of Arizona Press, 352. 
Martin J, Waldren S, O'Sullivan A, et al. 2001. The establishment of the threatened Irish plant seed bank. Biological Collections and Biodiversity, 127: 38 .

Milberg P, Andersson L, Thompson K. 2000. Large-seeded spices are less dependent on light for germination than small-seeded ones. Seed Science Research, 10(1): 99-104.

Musaddiq S, Khakwani S, Saleem M. 2015. Phytochemical studies on Halothamnus auriculus. Journal of Global Biosciences, 4(2): 1563-1570.

Negbi M, Tamari B. 1963. Germination of chlorophyllous and achlorophyllous seeds of Salsola volkensu and Allenia autrani. Israel Journal of Botany, 12: 124-135.

Noe G B, Zedler J B. 2000. Differential effects of four abiotic factors on the germination of salt marsh annuals. American Journal of Botany, 87(11): 1679-1692.

Omar S A S, Al-Mutawa Y, Zaman S. 2007. Vegetation of Kuwait: A Comprehensive Illustrative Guide to the Flora and Ecology of the Desert. Kuwait: Kuwait Institute for Scientific Research, 161.

Paul D. 2012. Osmotic stress adaptations in rhizobacteria. Journal of Basic Microbiology, 53(2): 101-110.

Probert R J. 2000. The role of temperature in the regulation of seed dormancy and germination. In: Fenner M. Seeds: the Ecology of Regeneration in Plant Communities. Wallingford: CABI, 261-292.

Rewald B, Leuschner C, Wiesman Z, et al. 2011. Influence of salinity on root hydraulic properties of three olive varieties. Plant Biosystems, 145(1): 12-22.

Ruiz M, Martín I, De la Cuadra C. 1999. Cereal seed viability after 10 years of storage in active and base germplasm collections. Field Crops Research, 64(3): 229-236.

Shaban M. 2013. Review on physiological aspects of seed deterioration. International Journal of Agriculture and Crop Sciences, 6 : 627.

Song J, Wang B S. 2015. Using euhalophytes to understand salt tolerance and to develop saline agriculture: Suaeda salsa as a promising model. Annals of Botany, 115(3): 541-553.

Song J, Shi W, Liu R, et al. 2016. The role of the seed coat in adaptation of dimorphic seeds of the euhalophyte Suaeda salsa to salinity. Plant Species Biology, 32(2): 107-114.

Song J I E, Feng G U, Tian C, et al. 2005. Strategies for adaptation of Suaeda physophora, Haloxylon ammodendron and Haloxylon persicum to a saline environment during seed-germination stage. Annals of Botany, 96(3): 399-405.

Takeno K, Yamaguchi H. 1991. Diversity in seed germination behavior in relation to heterocarpy in Salsola komarovii Iljin. The Botanical Magazine, 104(3): 207-215.

Ungar I A. 1995. Seed germination and seed-bank ecology in halophytes. In: Kigel J, Galili G. Seed Development and Germination. New York: Marcel Dekker Press, 599-628.

Wei Y, Dong M, Huang Z Y, et al. 2008. Factors influencing seed germination of Salsola affinis (Chenopodiaceae), a dominant annual halophyte inhabiting the deserts of Xinjiang, China. Flora, 203(2): 134-140.

Xing J, Cai M, Chen S, et al. 2013. Seed germination, plant growth and physiological responses of Salsola ikonnikoviito short-term NaCl stress. Plant Biosystems, 147(2): 285-297.

Xu Y, Liu R, Sui N, et al. 2016. Changes in endogenous hormones and seed-coat phenolics during seed storage of two Suaeda salsa populations. Australian Journal of Botany, 64: 325-332.

Yin L, Wang P. 1997. Distribution of $\mathrm{C}_{3}$ and $\mathrm{C}_{4}$ photosynthesis pathways of plants on the steppe of Northeastern China. ActaEcologicaSinica, 17: 113-123.

Zalenskiï O V. 1981. Pathway of carbon metabolism in halophytic desert species from Chenopodiaceae. Photosynthetica, 15: 244-255.

Zaman S, Padmesh S, Tawfiq H. 2010. Seed germination and viability of Salsola imbricata Forssk. International Journal of Biodiversity and Conservation, 2(12): 388-394.

Zaman S. 2013. Effect of five years storage on the germination of Zygophyllum qatarense Hadidi. Journal of Agriculture and Biodiversity Research, 2: 63-66. 